OPEN ACCESS

Edited by:

Zheng-Long $\mathrm{Xu}$,

Hong Kong Polytechnic University,

China

Reviewed by:

Xuelin Yang,

China Three Gorges University, China

Chao Lai,

Jiangsu Normal University, China

${ }^{*}$ Correspondence:

Jun $L i$

junli@wzu.edu.cn

Huile Jin

huilejin@wzu.edu.cn

Shun Wang

shunwang@wzu.edu.cn

Specialty section:

This article was submitted to

Electrochemistry,

a section of the journal

Frontiers in Chemistry

Received: 29 March 2021

Accepted: 10 May 2021

Published: 25 May 2021

Citation:

Lu G, Ye C, LiW, He X, Chen G, Li J, Jin H, Wang S and Wang J (2021) Advanced $\mathrm{Te}_{x} \mathrm{~S}_{y}$-C Nanocomposites for High-Performance Lithium

Ion Batteries.

Front. Chem. 9:687392.

doi: 10.3389/fchem.2021.687392

\section{Advanced $\mathrm{Te}_{\mathrm{x}} \mathrm{S}_{\mathrm{y}}-\mathrm{C}$ Nanocomposites for High-Performance Lithium Ion Batteries}

\author{
Guolong $L u^{1}$, Chunnuan $\mathrm{Ye}^{1}$, Wenyan $\mathrm{Li}^{1}$, Xuedong $\mathrm{He}^{1}$, Guang Chen ${ }^{1}$, Jun $\mathrm{Li}^{1 *}$, Huile $\mathrm{Jin}^{1 *}$, \\ Shun Wang ${ }^{1 *}$ and Jichang Wang ${ }^{2}$
}

${ }^{1}$ Nano-materials \& Chemistry Key Laboratory, Institute of New Materials and Industrial Technologies, Wenzhou University, Wenzhou, China, ${ }^{2}$ Department of Chemistry and Biochemistry, University of Windsor, Windsor, ON, Canada

This study is dedicated to expand the family of lithium-tellurium sulfide batteries, which have been recognized as a promising choice for future energy storage systems. Herein, a novel electrochemical method has been applied to engineer micro-nano $\mathrm{Te}_{\mathrm{x}} \mathrm{S}_{\mathrm{y}}$ material, and it is found that $T e_{x} S_{y}$ phases combined with multi-walled carbon nanotubes endow the as-constructed lithium-ion batteries excellent cycling stability and high rate performance. In the process of material synthesis, the sulfur was successfully embedded into the tellurium matrix, which improved the overall capacity performance. $T e_{x} S_{y}$ was characterized and verified as a micro-nano-structured material with less Te and more S. Compared with the original pure Te particles, the capacity is greatly improved, and the volume expansion change is effectively inhibited. After the assembly of $\mathrm{Li}_{-} \mathrm{Te}_{\mathrm{x}} \mathrm{S}_{\mathrm{y}}$ battery, the stable electrical contact and rapid transport capacity of lithium ions, as well as significant electrochemical performance are verified.

Keywords: sulfur telluride materials, electrochemical synthesis, composite materials, carbon nanotubes, lithium ion batteries

\section{INTRODUCTION}

Lithium-tellurium (Li-Te) batteries have attracted increasing attention owing to their high theoretical volume capacity (Liu et al., 2014; Ding et al., 2015; Li et al., 2017; Li G. et al., 2018; Yin et al., 2018; Wenjie Han et al., 2021), excellent electronic conductivity (He et al., 2017), and relieved shuttle effects compared to Li-sulfur, Li-selenium batteries (Yang et al., 2013; Eftekhari, 2017; Li Y. et al., 2018; Fan et al., 2019; Wang et al., 2020; Yu et al., 2020; Dai et al., 2021; Sun et al., 2021; Xiao et al., 2021). However, the huge volume expansion of Te severely deteriorates its practical applications towards the newly emerged battery systems. Therefore, how to alleviate or eliminate the volume variation is of great importance to fulfill the promising properties of Te. Since our first introduction of $\mathrm{Li}_{-} \mathrm{Te}_{\mathrm{x}} \mathrm{S}_{\mathrm{y}}$ battery ( $\mathrm{Li} \mathrm{J}$. et al., 2019), it seems there is a hope to light a new path to conquer the volume expansion challenge by the incorporation of sulfur elements inside tellurium lattice. Although our prepared $\mathrm{Li}-\mathrm{Te}_{\mathrm{x}} \mathrm{S}_{\mathrm{y}}$ cathode materials were not perfectly composed of pure $\mathrm{Te}_{\mathrm{X}} \mathrm{S}_{\mathrm{y}}$ phase, it has been demonstrated such $\mathrm{Te}_{\mathrm{x}} \mathrm{S}_{\mathrm{y}}$ phase is surprisingly stable in terms of in situ TEM observation, which can be survived during the repetitive cycling without obvious volume variation.

Many related works have tried to map the phase diagram of $\mathrm{Te}_{\mathrm{x}} \mathrm{S}_{\mathrm{y}}$, such as $\mathrm{Te}_{0.92} \mathrm{~S}_{0.08}, \mathrm{Te}_{0.04} \mathrm{~S}_{0.96}$, Te-n-S (where n represents the mass ratio) (Xu et al., 2018; Li et al., 2019a; Li et al., 2019b; Ge and Yin, 2019; Lee et al., 2019; Zhang et al., 2020). Sulfur incorporation leads to lattice distortion and $\mathrm{d}$-spacing enlargement of Te phase, rendering the composited $\mathrm{Te}_{\mathrm{x}} \mathrm{S}_{\mathrm{y}}$ with a fast transport of ions and electrons, as well as excellent structural stability during lithiation/delithiation processes (Chen et al., 
2020). Together with the superior electronic conductivity and enhanced reaction kinetics derived from $\mathrm{Te}, \mathrm{Li}-\mathrm{Te}_{\mathrm{x}} \mathrm{S}_{\mathrm{y}}$ batteries exhibit extraordinary energy storage performance and foreseeable bright future for next-generation battery systems.

In this work, we have attempted to design new types of $\mathrm{Te}_{\mathrm{x}} \mathrm{S}_{\mathrm{y}}$ phases and fill some blank in $\mathrm{Te}_{\mathrm{x}} \mathrm{S}_{\mathrm{y}}$ phase diagram by applying different kinds of sulfur sources during the nonlinear electrochemical synthesis of $\mathrm{Te}_{\mathrm{x}} \mathrm{S}_{\mathrm{y}}$ ( $\mathrm{Li}$ et al., 2019a). The experimental results suggested that different sulfur sources give rise to distinguished lattice distortions of $\mathrm{Te}$, and thus different types of $\mathrm{Te}_{\mathrm{x}} \mathrm{S}_{\mathrm{y}}$ phases, among which, $\mathrm{Na}_{2} \mathrm{~S}$-derived $\mathrm{Te}_{\mathrm{x}} \mathrm{S}_{\mathrm{y}}$ ball milled with multi-walled carbon nanotubes endows $\mathrm{Li}^{-} \mathrm{Te}_{\mathrm{x}} \mathrm{S}_{\mathrm{y}}$ batteries profound volumetric capacity performance and high cycling stability.

\section{MATERIALS AND METHODS}

\section{Synthesis of $\mathrm{Te}_{\mathrm{x}} \mathrm{S}_{\mathrm{y}}$ Micro-nano Materials}

Sodium sulfide $\left(\mathrm{Na}_{2} \mathrm{~S} \cdot 9 \mathrm{H}_{2} \mathrm{O}\right)$, tellurium ingot (Te) and sodium hydroxide $(\mathrm{NaOH})$ were all purchased from Aladdin. The sintered $\mathrm{Te}$ rod, platinum wire and calomel electrode $(\mathrm{Hg} /$ $\mathrm{HgCl}_{2}$ ) was used as the working, counter and reference electrode, respectively. The three-electrode system was employed in an equilateral triangle manner with a distance of $1.8 \mathrm{~cm}$. Before experiments, the working and counter electrodes were cleaned with ultrasonic cleaner (Branson 1510, United States) for $10 \mathrm{~min}$, and then rinsed with distilled water. The temperature of reaction cell was maintained at $25.0^{\circ} \mathrm{C}$. The electrochemical synthesis experiments were carried out at the CHI 660e Electrochemical Workstation (Shanghai Chenhua). A typical solution preparation is to dissolve $0.5 \mathrm{~mol} \mathrm{~L}^{-1} \mathrm{NaOH}$ first, and then add $0.5 \mathrm{~mol} \mathrm{~L}^{-1} \mathrm{Na}_{2} \mathrm{~S} \cdot 9 \mathrm{H}_{2} \mathrm{O}$ (other sulfur sources with different concentrations were specified) to the solution to get a clear solution. The voltage window of $0-1.5 \mathrm{~V}$ was set by cyclic voltammetry $(\mathrm{CV})$ with a scan rate of $0.1 \mathrm{mV} \mathrm{s}^{-1}$, and the electrochemical reaction was carried out by $3 \mathrm{CV}$ cycles. The black solid products were finally collected, cleaned and centrifuged, which was later identified as $\mathrm{Te}_{\mathrm{x}} \mathrm{S}_{\mathrm{y}}$ micro-nano materials.

\section{Synthesis of $\mathrm{Te}_{\mathrm{x}} \mathrm{S}_{\mathrm{y}}-\mathrm{C}$ Nanocomposites}

The above as-prepared $\mathrm{Te}_{\mathrm{x}} \mathrm{S}_{\mathrm{y}}$ materials were mixed with certain mass ratio of multi-walled carbon nanotubes (purchased from XFNANO, $50 \mu \mathrm{m}$ in length, $8-15 \mathrm{~nm}$ in diameter, purity $>95 \%$ ) by using a ball milling machine (QM-3C, Nanjing University). After fully mixing for $20 \mathrm{~h}$, the composites of $\mathrm{Te}_{\mathrm{x}} \mathrm{S}_{\mathrm{y}}$-multi-walled carbon nanotubes $\left(\mathrm{Te}_{\mathrm{x}} \mathrm{S}_{\mathrm{y}}-\mathrm{C}\right)$ were obtained.

\section{Characterization}

Scanning electron microscopy (SEM) was performed on a Nova Nanosem 200 system with an acceleration voltage of $15 \mathrm{kV}$. Transmission electron microscopy (TEM) and high resolution transmission electron microscopy (HRTEM) were conducted on JEM-2100F. Energy dispersive X-ray energy spectrum (EDX) and TEM measurements were performed simultaneously. Raman spectroscopy (INVIA, Renishaw, United Kingdom) was carried out at an ambient temperature with a $514 \mathrm{~nm}$ laser excitation. X-ray photoelectron spectroscopy (XPS) was performed in the spectrometer from Kratos axis Ultradld, using Mono $\mathrm{Al} \mathrm{Ka}$ radiation power of $120 \mathrm{~W}(8 \mathrm{~mA}, 15 \mathrm{kV})$. X-ray diffraction (XRD) was tested by using a $\mathrm{Cu}-\mathrm{Ka}$ radiation $(\mathrm{A}=0.15406 \mathrm{~nm})$ on the Bruker D8 Advanced Diffractometer with a data acquisition range of $10^{\circ}-80^{\circ}$ and sweep rate of $0.02^{\circ} \mathrm{s}^{-1}$. Thermogravimetric analysis (TGA) was performed on Perkin-Elmer PRIS1 TGA/Clarus SQ $8 \mathrm{~T}$ at a heating rate of $5^{\circ} \mathrm{C} \mathrm{min}^{-1}$.

\section{Electrochemical Test}

The electrochemical properties of $\mathrm{Te}_{\mathrm{x}} \mathrm{S}_{\mathrm{y}}-\mathrm{C}$ nanocomposites were studied by using the 2025 coin battery on the Neware-battery testing system. The working electrode was prepared by pasted a mixture of $70 \mathrm{wt} \% \mathrm{Te}_{\mathrm{x}} \mathrm{S}_{\mathrm{y}}-\mathrm{C}$ nanocomposites, $15 \mathrm{wt} \%$ acetylene black and $15 \mathrm{wt} \%$ polyvinylidene fluoride (PVDF) on the aluminum foil. The mass loading of the active material on the electrode was $1-2 \mathrm{mg} \mathrm{cm}^{-2}$, and the lithium metal wafer was used as the counter electrode. The electrolyte was containing $1 \mathrm{~mol} \mathrm{~L}^{-1}$ lithium bis(trifluoromethane)sulfonimide (LiTFSI) electrolyte, $2 \% \mathrm{LiNO}_{3}$, and 1,3-dioxolane (DOL) and 1,2-dimethoxyethane $(\mathrm{DME})$ (volume ratio $=1: 1$ ). The battery was assembled in a glove box filled with pure argon gas.

\section{RESULTS AND DISCUSSION}

In this work, we have tried various sulfur sources to fabricate different types of $\mathrm{Te}_{\mathrm{x}} \mathrm{S}_{\mathrm{y}}$ phases via a nonlinear electrochemical approach. By changing the actively reducing sulfur species such as sodium dimethyldithiocarbamate $\left(\mathrm{C}_{3} \mathrm{H}_{6} \mathrm{NNaS}_{2}\right)$ and thiourea $\left(\mathrm{CH}_{4} \mathrm{~N}_{2} \mathrm{~S}\right)$, sodium hydrogen sulfide $(\mathrm{NaHS})$ and sodium sulfide $\left(\mathrm{Na}_{2} \mathrm{~S}\right)$ for the production of $\mathrm{Te}_{\mathrm{x}} \mathrm{S}_{\mathrm{y}}$ phases, distinctive micro-nano structured $\mathrm{Te}_{\mathrm{x}} \mathrm{S}_{\mathrm{y}}$ materials were engineered in Figure 1 via the control of nonlinear electrochemical dynamics in Supplementary Figure S2. The scanning electron microscope (SEM) images indicated that the presence of $\mathrm{Na}_{2} \mathrm{~S}$ could lead to a distinguished morphology (flakes) compared to that of other products (rods). More importantly, Raman spectra in Supplementary Figure S3 revealed that the sulfur content was maximized in $\mathrm{Te} @ \mathrm{Na}_{2} \mathrm{~S}$, denoted as $\mathrm{Te}_{\mathrm{x}} \mathrm{S}_{\mathrm{y}}$ phases prepared by $\mathrm{Na}_{2} \mathrm{~S}$. The optimal concentration of $\mathrm{Na}_{2} \mathrm{~S}$ for the construction of nano-flaked $\mathrm{Te}_{\mathrm{x}} \mathrm{S}_{\mathrm{y}}$ phases was determined as $0.5 \mathrm{~mol} \mathrm{~L}^{-1}$. As the concentration of $\mathrm{Na}_{2} \mathrm{~S}$ was increased, the nano-flaked $\mathrm{Te}_{\mathrm{x}} \mathrm{S}_{\mathrm{y}}$ phases were broken into randomly downsized nano-particles, as shown in Supplementary Figure S4. Surprisingly, the increasing concentration of $\mathrm{Na}_{2} \mathrm{~S}$ also led to an overwhelmed Raman peak intensity of sulfur than tellurium in Supplementary Figure S5.

Transmission electron microscopy (TEM) characterization of $\mathrm{Te}_{\mathrm{x}} \mathrm{S}_{\mathrm{y}}$ material was obtained when the concentration of $\mathrm{Na}_{2} \mathrm{~S}$ was set to $2.0 \mathrm{~mol} \mathrm{~L}^{-1}$. It can be found that the downsized nanoparticles have a very poor crystallinity from Figures $\mathbf{2 A , B}$, in which a typical lattice parameter is emerged in a typically selected area, with a d-spacing of $0.334 \mathrm{~nm}$ representing $\mathrm{Te}(011)$ plane. The observed lattice spacing agrees with the hexagonal element Te phase. Therefore, the 

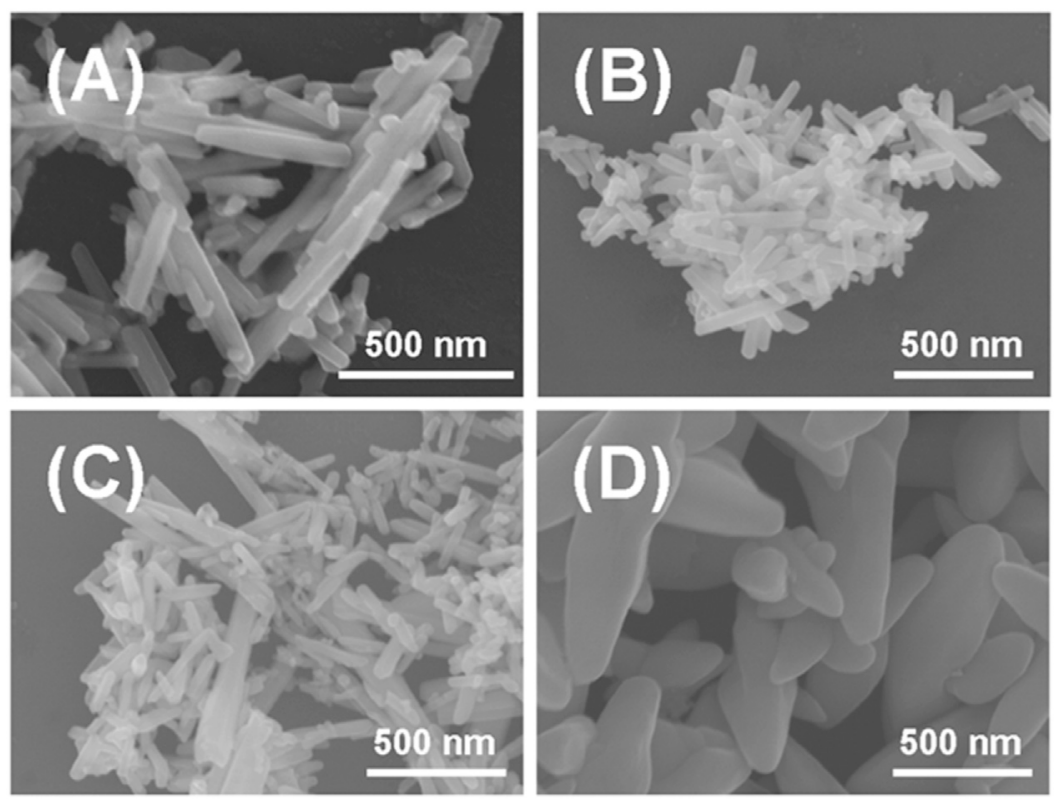

FIGURE 1 | SEM image of solid products prepared by electrochemical cyclic voltammetry with different types of precursor S sources and the same concentration of $0.5 \mathrm{~mol} \mathrm{~L}^{-1}$ : (A) $\mathrm{Te} @ \mathrm{C}_{3} \mathrm{H}_{6} \mathrm{NNaS}_{2}$, (B) Te@ $\mathrm{CH}_{4} \mathrm{~N}_{2} \mathrm{~S}$, (C) Te@NaHS, (D) Te@ $\mathrm{Na}_{2} \mathrm{~S}$.
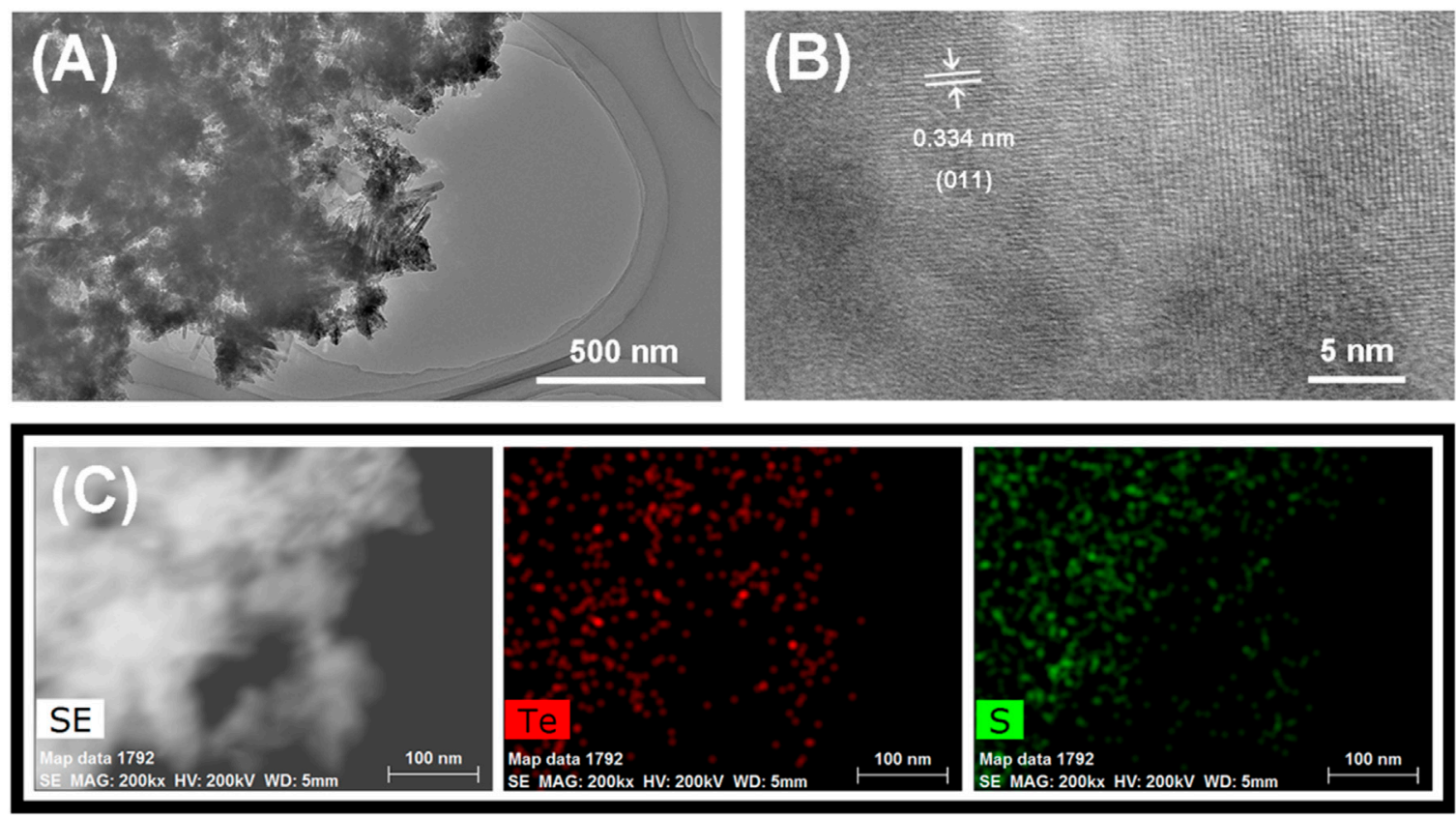

FIGURE 2 | Characterization of $\mathrm{Te}_{\mathrm{x}} \mathrm{S}_{\mathrm{y}}$ : (A) TEM, (B) HRTEM, (C) EDS.

as-obtained materials are not composed of pure $\mathrm{Te}_{\mathrm{x}} \mathrm{S}_{\mathrm{y}}$ phases. Another evidence is from XRD analysis in Supplementary Figure S5B, where the XRD peaks are broadened as the concentration of $\mathrm{Na}_{2} \mathrm{~S}$ is increased, indicating the incorporation of sulfur in Te crystalline causes the poor crystallinity. Furthermore, $\mathrm{Te}_{\mathrm{x}} \mathrm{S}_{\mathrm{y}}$ phases are dominated in the as-prepared materials, strongly supported by the homogeneous distribution of $\mathrm{Te}$ and $\mathrm{S}$ elements in Figure 2C.

In order to further study the composition of $\mathrm{Te}_{\mathrm{x}} \mathrm{S}_{\mathrm{y}}$ component and the formation mechanism of Te-S bond, the product synthesized 

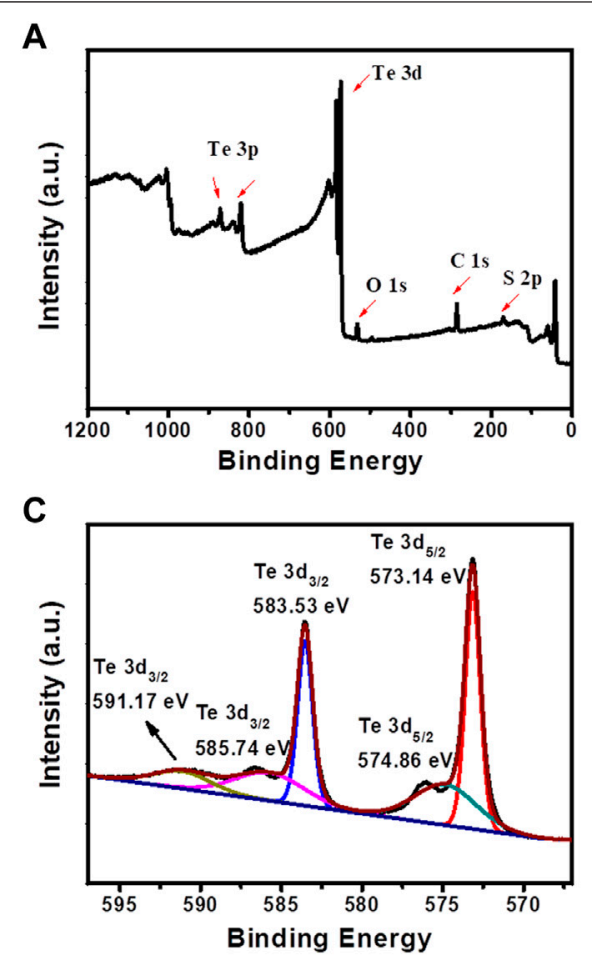

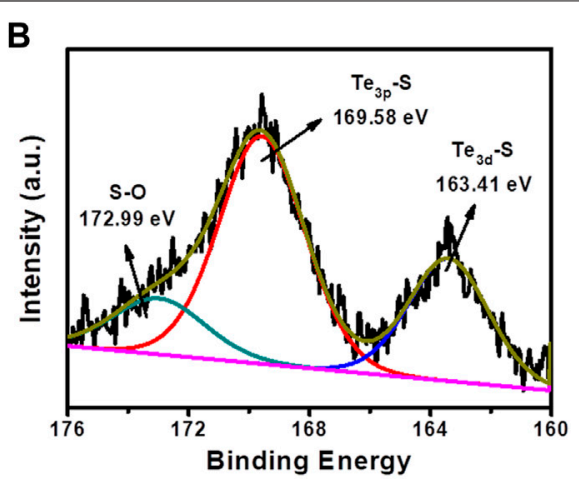

D

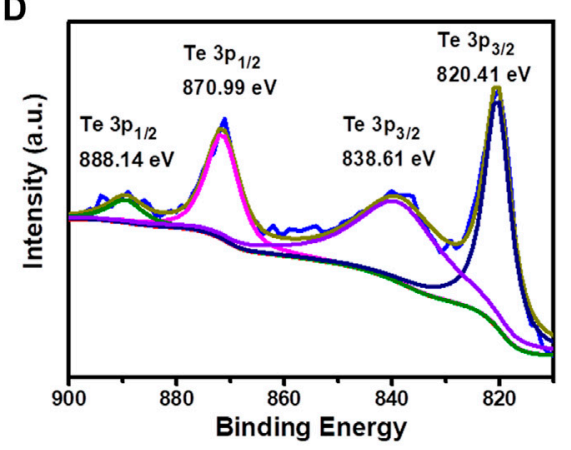

FIGURE 3 | XPS spectra of $\mathrm{Te}_{x} \mathrm{~S}_{\mathrm{y}}$ products prepared at $\mathrm{Na}_{2} \mathrm{~S}$ concentration of $2.0 \mathrm{~mol} \mathrm{~L}^{-1}$ : (A) Survey spectrum, (B) S 2p, (C) Te 3d, (D) Te 3p.

by $2.0 \mathrm{~mol} \mathrm{~L}^{-1} \mathrm{Na}_{2} \mathrm{~S}$ solution was selected for XPS characterization (Figure 3). Figure 3A presented a XPS survey image of $\mathrm{Te}_{\mathrm{x}} \mathrm{S}_{\mathrm{y}}$ components possessing the main elements of Te and S. Figure 3B displayed three types of sulfur bonding, where 163.41, 169.58 and $172.99 \mathrm{eV}$ are the electron binding energies of $\mathrm{Te}_{3 \mathrm{~d}}-\mathrm{S}$ bond, $\mathrm{Te}_{3 \mathrm{p}}-\mathrm{S}$ bond and S-O bond respectively. It can be seen from Figures 3C,D that there were multiple types of Te oxidized states. 573.14 and $574.86 \mathrm{eV}$ are the electron binding energies of Te $3 \mathrm{~d}_{5 / 2}$ bond, and $583.53,585.74$ and $591.17 \mathrm{eV}$ are the electron binding energies of $\mathrm{Te}$ $3 \mathrm{~d}_{3 / 2}$ bond, demonstrating that Te element in $\mathrm{Te}_{\mathrm{x}} \mathrm{S}_{\mathrm{y}}$ component exists in the form of $\mathrm{Te}^{4+}$ and $\mathrm{Te}^{6+}$. Therefore, it can be speculated that the formation of Te-S bond is derived from the electrochemical oxidation of $\mathrm{Te}$ on the main electrode to form $\mathrm{TeO}_{4}{ }^{2-}$ and $\mathrm{TeO}_{3}{ }^{2-}$, which are then chemically reduced by different organic or inorganic sulfides in this study to form $\mathrm{Te}_{\mathrm{x}} \mathrm{S}_{\mathrm{y}}$. The overall reaction mechanism is followed by the electrochemical-chemical (EC) reaction pathway, similar as the first two steps of our previous study (Li J. et al., 2019). The distinguished reducibility of organic and inorganic sulfides enabled the self-assembly of $\mathrm{Te}_{\mathrm{x}} \mathrm{S}_{\mathrm{y}}$ with different nano-micro morphologies and chemical compositions, rendering $\mathrm{Te}_{\mathrm{x}} \mathrm{S}_{\mathrm{y}}$ with varied physicochemical properties for seeking the promising electrochemical performance.

However, compared to our previous study (Li J. et al., 2019), the asprepared $\mathrm{Te}_{\mathrm{x}} \mathrm{S}_{\mathrm{y}}$ phases without any confinements from carbon hosts were failed to contribute a promising electrochemical performance towards lithium ion batteries. As shown in Supplementary Figure S6, high charge transfer resistance, poor cycling stability and rate performance seems a total failure. Therefore, in this work we applied multi-walled carbon nanotubes (MWCNTs) as a carbon host to confine the $\mathrm{Te}_{\mathrm{x}} \mathrm{S}_{\mathrm{y}}$ phases. Astonishingly, the ball milling of $\mathrm{Te}_{\mathrm{x}} \mathrm{S}_{\mathrm{y}}$ phases with MWCNTs rendered the $\mathrm{Te}_{\mathrm{x}} \mathrm{S}_{\mathrm{y}}\left(\mathrm{Na}_{2} \mathrm{~S}\right) / \mathrm{MWCNT}$ with a strange thermal degradation feature, that is, $\mathrm{Te}_{\mathrm{x}} \mathrm{S}_{\mathrm{y}}$ phases actually reacted with MWCNTs, and resulted in a two-stage thermal degradation of $\mathrm{Te}_{\mathrm{x}} \mathrm{S}_{\mathrm{y}}$ in Supplementary Figure S8B. In comparison with $\mathrm{Te}_{\mathrm{x}} \mathrm{S}_{\mathrm{y}}$, the $\mathrm{Te}_{\mathrm{x}} \mathrm{S}_{\mathrm{y}}-\mathrm{C}$ possessed a distinctive thermal degradation kinetics, where the less mass ratio of $\mathrm{Te}_{\mathrm{x}} \mathrm{S}_{\mathrm{y}}: \mathrm{C}$ such as 5:5 and 3:7 could lead to the lower decomposition temperatures $\left(\sim 630^{\circ} \mathrm{C}\right.$ as shown in Supplementary Table S1) than that of pure $\mathrm{Te}_{\mathrm{x}} \mathrm{S}_{\mathrm{y}}$ and the high mass ratio of $\mathrm{Te}_{\mathrm{x}} \mathrm{S}_{\mathrm{y}}: \mathrm{C}=7: 3\left(\sim 700^{\circ} \mathrm{C}\right)$, indicating the rearrangement of $\mathrm{Te}_{\mathrm{x}} \mathrm{S}_{\mathrm{y}}$ phases was occurred in the presence of appropriate amounts of MWCNTs.

Afterwards, the $\mathrm{Te}_{\mathrm{x}} \mathrm{S}_{\mathrm{y}}\left(\mathrm{Na}_{2} \mathrm{~S}\right) / \mathrm{MWCNT}$ composited materials with different mixing ratios were further evaluated by battery performance test, as shown in Figure 4. Figure 4A showed a diagram of the rate performance of $\mathrm{Te}_{\mathrm{x}} \mathrm{S}_{\mathrm{y}}\left(\mathrm{Na}_{2} \mathrm{~S}\right) / \mathrm{MWCNT}$ composites with different mixing ratios. It is worth noting that the materials with composite ratio of 5:5 have relatively better rate performance than the other two materials. Electrochemical impedance spectroscopy (EIS) of $\mathrm{Te}_{\mathrm{x}} \mathrm{S}_{\mathrm{y}}\left(\mathrm{Na}_{2} \mathrm{~S}\right) / \mathrm{MWCNT}$ composited batteries with different mixing ratios were also tested in Figure 4B. As it can be seen, the increased amount of multi-walled carbon nanotubes would worsen the charge transfer, suggesting an integrated interfacial effects between $\mathrm{Te}_{\mathrm{x}} \mathrm{S}_{\mathrm{y}}$ and MWCNTs. In addition, Figure 4C showed the charge-discharge curves of lithium ion battery with a mixture ratio of 5:5 at different current densities. The first charge-discharge curves suggest a relatively high initial Coulombic efficiency. Figures 4D-F presented that the compound ratio of 5:5 $\mathrm{Te}_{\mathrm{x}} \mathrm{S}_{\mathrm{y}}\left(\mathrm{Na}_{2} \mathrm{~S}\right) / \mathrm{MWCNT}$ composited battery exhibits a promising cycling behavior at $1.0,2.0,5.0 \mathrm{~A} \mathrm{~g}^{-1}$, in which a 

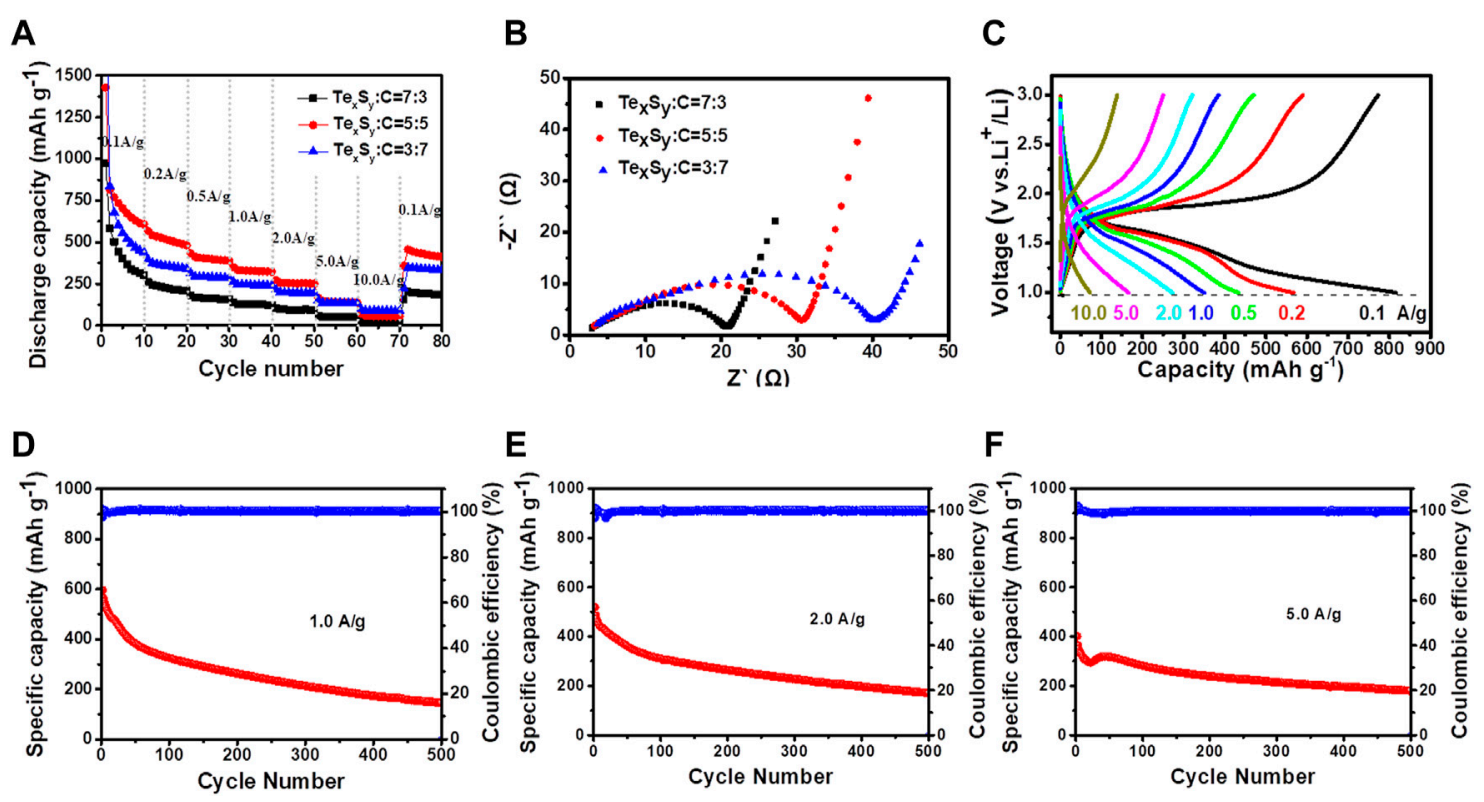

FIGURE 4 | The electrochemical performance of $\mathrm{Te}_{x} \mathrm{~S}_{y}\left(\mathrm{Na}_{2} \mathrm{~S}\right) / \mathrm{MWCNT}$ composites: (A) rate performance, (B) EIS measurements, (C) charging/discharging curves at varied current densities towards the mass ratio of 5:5 Te $\mathrm{S}_{y}\left(\mathrm{Na}_{2} \mathrm{~S}\right) / \mathrm{MWCNT}$ composites, cycling stability and Coulomb efficiency of 5:5 Te $\mathrm{S}_{\mathrm{y}}\left(\mathrm{Na} \mathrm{S}_{2} \mathrm{~S}\right) / \mathrm{MWCNT}$ composites at the current density of (D) $1.0 \mathrm{~A} \mathrm{~g}^{-1}$, (E) $2.0 \mathrm{~A} \mathrm{~g}^{-1}$, (F) $5.0 \mathrm{~A} \mathrm{~g}^{-1}$.

larger current density would lead to a better cycling stability, indicating a potential fast-charging application in rechargeable batteries. When the current density was set to $5.0 \mathrm{~A} \mathrm{~g}^{-1}$, the first specific capacity was obtained as $406.56 \mathrm{mAh} \mathrm{g}^{-1}$, and capacity retention remained as $45.03 \%$ after 500 cycles. While the current density was set less than $5.0 \mathrm{Ag}^{-1}$, the rate performance behaved much worse than that at $5.0 \mathrm{Ag}^{-1}$, demonstrating $\mathrm{Te}_{\mathrm{x}} \mathrm{S}_{\mathrm{y}}\left(\mathrm{Na}_{2} \mathrm{~S}\right)$ / MWCNT composite material is more suitable for high rate performance in lithium ion batteries. The as-prepared lithiumtellurium sulfide battery may potentially tackle the cons of low rate performance in lithium-sulfur battery, and high volume expansion and low capacity performance in lithium-tellurium battery.

\section{CONCLUSION}

In summary, we designed a promising electrochemical method to control the synthesis of $\mathrm{Te}_{\mathrm{x}} \mathrm{S}_{\mathrm{y}}$ micro-nano structured composites, verified the formation mechanism and qualitatively evaluated the influence of chemical composition on the battery performance. The morphology and composition ratio of $\mathrm{Te}_{\mathrm{x}} \mathrm{S}_{\mathrm{y}}\left(\mathrm{Na}_{2} \mathrm{~S}\right) / \mathrm{MWCNT}$ were controlled by the types of sulfur sources, concentration and synthetic voltage. In addition, MWCNTs as an ideal carbon host were used for the confinement of the dissolution of tellurium and sulfur, which significantly improved the electrochemical performance of the $\mathrm{Te}_{\mathrm{x}} \mathrm{S}_{\mathrm{y}}\left(\mathrm{Na}_{2} \mathrm{~S}\right) / \mathrm{MWCNT}$ composited battery. The nonlinear electrochemical synthetic method and ball milling aftertreatments provide a new way for the sustainable development of high-performance Li battery manufacturing.

\section{DATA AVAILABILITY STATEMENT}

The original contributions presented in the study are included in the article/Supplementary Material, further inquiries can be directed to the corresponding authors.

\section{AUTHOR CONTRIBUTIONS}

JL, HJ, and SW designed the experiments. GL and CY performed the material synthesis, characterization and battery tests. GL analyzed the data and drafted the manuscript. JL made the major revision. All authors participated in discussions.

\section{FUNDING}

This work was supported by the National Natural Science Foundation of China (51872209, 51972239, and 52072273), the Zhejiang Provincial Natural Science Foundation of China (Z21E020002) and Natural Sciences and Engineering Research Council of Canada (NSERC).

\section{SUPPLEMENTARY MATERIAL}

The Supplementary Material for this article can be found online at: https://www.frontiersin.org/articles/10.3389/fchem.2021.687392/ full\#supplementary-material 


\section{REFERENCES}

Chen, Z., Zhao, Y., Mo, F., Huang, Z., Li, X., Wang, D., et al. (2020). MetalTellurium Batteries: A Rising Energy Storage System. Small Structures 1, 2000005. doi:10.1002/sstr.202000005

Dai, Y. Y., Xu, C. M., Liu, X. H., He, X. X., Yang, Z., Lai, W. H., et al. (2021). Manipulating Metal-Sulfur Interactions for Achieving High-performance $S$ Cathodes for Room Temperature Li/Na-Sulfur Batteries. Carbon Energy. doi:10.1002/cey2.101

Ding, N., Chen, S.-F., Geng, D.-S., Chien, S.-W., An, T., Hor, T. S. A., et al. (2015). Tellurium@Ordered Macroporous Carbon Composite and Free-Standing Tellurium Nanowire Mat as Cathode Materials for Rechargeable LithiumTellurium Batteries. Adv. Energ. Mater. 5, 1401999. doi:10.1002/aenm. 201401999

Eftekhari, A. (2017). The Rise of Lithium-Selenium Batteries. Sustain. Energ. Fuels 1, 14-29. doi:10.1039/c6se00094k

Fan, L., Li, M., Li, X., Xiao, W., Chen, Z., and Lu, J. (2019). Interlayer Material Selection for Lithium-Sulfur Batteries. Joule 3, 361-386. doi:10.1016/j.joule. 2019.01.003

Ge, X., and Yin, L. (2019). S-doping Induced Boosted Electrochemical Redox Kinetics in Te1-xSx Nanorod Cathodes for High Volumetric Capacity Li-Te Batteries. Energ. Storage Mater. 20, 89-97. doi:10.1016/j.ensm.2019.05.012

He, J., Lv, W., Chen, Y., Wen, K., Xu, C., Zhang, W., et al. (2017). TelluriumImpregnated Porous Cobalt-Doped Carbon Polyhedra as Superior Cathodes for Lithium-Tellurium Batteries. ACS Nano 11, 8144-8152. doi:10.1021/acsnano. $7 \mathrm{~b} 03057$

Lee, S., Choi, H., and Eom, K. (2019). Enhancing the Electrochemical Performances of a Tellurium-Based Cathode for a High-Volumetric Capacity Li Battery via a High-Energy ball Mill with Sulfur Edge-Functionalized Carbon. J. Power Sourc. 430, 112-119. doi:10.1016/j.jpowsour.2019.05.002

Li, G., Wang, X., Seo, M. H., Li, M., Ma, L., Yuan, Y., et al. (2018). Chemisorption of Polysulfides through Redox Reactions with Organic Molecules for LithiumSulfur Batteries. Nat. Commun. 9, 705. doi:10.1038/s41467-018-03116-Z

Li, J., Yuan, Y., Jin, H., Lu, H., Liu, A., Yin, D., et al. (2019). One-step Nonlinear Electrochemical Synthesis of TexSy@PANI Nanorod Materials for Li-TexSy Battery. Energ. Storage Mater. 16, 31-36. doi:10.1016/j.ensm.2018.04.019

Li, S., Han, Z., Hu, W., Peng, L., Yang, J., Wang, L., et al. (2019b). Manipulating Kinetics of Sulfurized Polyacrylonitrile with Tellurium as Eutectic Accelerator to Prevent Polysulfide Dissolution in Lithium-Sulfur Battery under Dissolution-Deposition Mechanism. Nano Energy 60, 153-161. doi:10.1016/ j.nanoen.2019.03.023

Li, S., Zeng, Z., Yang, J., Han, Z., Hu, W., Wang, L., et al. (2019a). High Performance Room Temperature Sodium-Sulfur Battery by Eutectic Acceleration in Tellurium-Doped Sulfurized Polyacrylonitrile. ACS Appl. Energ. Mater. 2, 2956-2964. doi:10.1021/acsaem.9b00343

Li, Y., Hu, L., Shen, B., Dai, C., Xu, Q., Liu, D., et al. (2017). Rib-like Hierarchical Porous Carbon as Reservoir for Long-Life and High-Rate Li-Te Batteries. Electrochimica Acta 250, 10-15. doi:10.1016/j.electacta.2017.07.124
Li, Y., Wang, M.-Q., Chen, Y., Hu, L., Liu, T., Bao, S., et al. (2018). Muscle-like Electrode Design for Li-Te Batteries. Energ. Storage Mater. 10, 10-15. doi:10. 1016/j.ensm.2017.07.017

Liu, Y., Wang, J., Xu, Y., Zhu, Y., Bigio, D., and Wang, C. (2014). Lithium-tellurium Batteries Based on Tellurium/porous Carbon Composite. J. Mater. Chem. A. 2, 12201-12207. doi:10.1039/c4ta02075h

Sun, J., Du, Z., Liu, Y., Ai, W., Wang, K., Wang, T., et al. (2021). State-Of-The-Art and Future Challenges in High Energy Lithium-Selenium Batteries. Adv. Mater. 33, 2003845. doi:10.1002/adma.202003845

Wang, P., Gong, Z., Ye, K., Kumar, V., Zhu, K., Sha, L., et al. (2020). Design and Construction of a Three-dimensional Electrode with Biomass-derived Carbon Current Collector and Water-soluble Binder for High-sulfur-loading Lithiumsulfur Batteries. Carbon Energy 2, 635-645. doi:10.1002/cey2.49

Wenjie Han, Q. L., Zhu, H., Luo, D., Qin, X., and Li, B. (2021). Hierarchical Porous Graphene Bubble as Host Materials for Advanced Lithium Sulfur Battery Cathode. Front. Chem. doi:10.3389/fchem.2021.653476

Xiao, Q., Yang, J., Wang, X., Deng, Y., Han, P., Yuan, N., et al. (2021). Carbonbased Flexible Self-supporting Cathode for Lithium-sulfur Batteries: Progress and Perspective. Carbon Energy. doi:10.1002/cey2.96

Xu, K., Liu, X., Liang, J., Cai, J., Zhang, K., Lu, Y., et al. (2018). Manipulating the Redox Kinetics of Li-S Chemistry by Tellurium Doping for Improved Li-S Batteries. ACS Energ. Lett. 3, 420-427. doi:10.1021/acsenergylett.7b01249

Yang, C.-P., Xin, S., Yin, Y.-X., Ye, H., Zhang, J., and Guo, Y.-G. (2013). An Advanced Selenium-Carbon Cathode for Rechargeable Lithium-Selenium Batteries. Angew. Chem. Int. Ed. 52, 8363-8367. doi:10.1002/anie.201303147

Yin, H., Yu, X.-X., Yu, Y.-W., Cao, M.-L., Zhao, H., Li, C., et al. (2018). Tellurium Nanotubes Grown on Carbon Fiber Cloth as Cathode for Flexible All-SolidState Lithium-Tellurium Batteries. Electrochimica Acta 282, 870-876. doi:10.1016/j.electacta.2018.05.190

Yu, Z., Liu, M., Guo, D., Wang, J., Chen, X., Li, J., et al. (2020). Radially Inwardly Aligned Hierarchical Porous Carbon for Ultra-Long-Life Lithium-Sulfur Batteries. Angew. Chem. Int. Ed. 59, 6406-6411. doi:10.1002/anie.201914972

Zhang, W., Zhang, Y., Peng, L., Li, S., Wang, X., Cheng, S., et al. (2020). Elevating Reactivity and Cyclability of All-Solid-State Lithium-Sulfur Batteries by the Combination of Tellurium-Doping and Surface Coating. Nano Energy 76, 105083. doi:10.1016/j.nanoen.2020.105083

Conflict of Interest: The authors declare that the research was conducted in the absence of any commercial or financial relationships that could be construed as a potential conflict of interest.

Copyright (C) $2021 \mathrm{Lu}, \mathrm{Ye}, \mathrm{Li}, \mathrm{He}$, Chen, Li, Jin, Wang and Wang. This is an openaccess article distributed under the terms of the Creative Commons Attribution License (CC BY). The use, distribution or reproduction in other forums is permitted, provided the original author(s) and the copyright owner(s) are credited and that the original publication in this journal is cited, in accordance with accepted academic practice. No use, distribution or reproduction is permitted which does not comply with these terms. 